\title{
PERCEPÇÕES DOS GESTORES DE ESCOLAS PÚBLICAS MUNICIPAIS DE CAMPINAS-SP SOBRE O PROGRAMA BOLSA FAMÍLIA
}

\author{
PERCEPTIONS OF THE MANAGERS OF MUNICIPAL PUBLIC \\ SCHOOLS IN CAMPINAS-SP ON THE BOLSA FAMÍLIA PROGRAM
}

\section{PERCEPCIONES DE LOS DIRECTIVOS DE LAS ESCUELAS PÚBLICAS DE CAMPINAS-SP EN EL PROGRAMA BOLSA FAMILIA}

Lineu SANTOS ${ }^{\mathrm{I}}$

ANDRÉ PIRES $^{\mathrm{I}}$

Resumo Este artigo apresenta resultados de uma investigação que entrevistou gestores, diretores e coordenadores pedagógicos de quatro escolas municipais de Campinas-SP, localizadas em regiões de maior vulnerabilidade social e que atingiram o Índice de Desenvolvimento da Educação Básica - IDEB projetado para 2013. A pesquisa teve como objetivo identificar se, em escolas com alunos bolsistas do Programa Bolsa Família (PBF) e relativamente bem avaliadas pelo IDEB, haveria algum tipo de discussão ou de prática pedagógica relacionada aos beneficiários. As entrevistas realizadas nesses locais apontaram para um conhecimento por parte dos gestores em relação à condicionalidade da frequência escolar do PBF e também mostrou que não se desenvolvem práticas pedagógicas voltadas especificamente a esse público. A inexistência de tais práticas, na visão dos entrevistados, se dá a fim de evitar a discriminação dos bolsistas ou pelos efeitos da pobreza serem invisibilizados dentro do ambiente escolar. Os entrevistados acreditam no potencial do Programa, mas são céticos em relação ao rompimento do chamado ciclo intergeracional da pobreza. Palavras-chave: Programa Bolsa Família; Frequência Escolar; Práticas Pedagógica.

\footnotetext{
Pontifícia Universidade Católica de Campinas - PUC-Campinas. Campinas/SP - Brasil.
} 
AbSTRaCt This paper presents findings of a research which interviewed managers, directors and coordinators of four municipal schools in Campinas about the federal Cash Transfer program Bolsa Família. The schools were located in regions of greatest social vulnerability, and who have attained the Development Index of Basic Education - IDEB target for 2013. The research aimed to identify if, in schools with student that participated in the Program and were relatively well-evaluated by the IDEB, there would be some kind of discussion or teaching practice related to the beneficiaries. The interviews conducted at these sites have pointed to a knowledge on the part of managers in relation to the PBF, with a greater emphasis on school attendance and also showed that they do not develop pedagogical practices aimed specifically at this audience, this issue caused surprise to the school managers. The absence of such practices, in the view of the respondents if it gives in order to avoid the discrimination of the fellows or by the effects of poverty being invisible within this environment, so the respondents believe in the potential of the Program, but are skeptical in relation to the breach of the so-called cycle of intergenerational poverty.

Key-words: Cash Transfer Program; School Attendance; Pedagogic Practice.

RESUmen Este artículo presenta los resultados de una investigación que entrevistó a los gerentes, directores y coordinadores de 4 cuatro escuelas públicas en Campinas-SP, situadas en las zonas de mayor vulnerabilidad social y que han llegado al Índice de Desarrollo de la Educación Básica - IDEB diseñada para 2013 sobre el programa de subvenciones familia. La investigación tuvo como objetivo identificar si en las escuelas con estudiantes becados del Programa y relativamente bien evaluados por IDEB, que habría algún tipo de discusión o la enseñanza práctica relacionada con los beneficiarios. Las entrevistas apuntaban a éstos el conocimiento local de administradores en relación con GMP, con mayor énfasis en la asistencia escolar y también mostraron que no desarrolla las prácticas pedagógicas especialmente dirigidas a este público, esta pregunta causó sorpresa a los administradores escolares. La falta de tales prácticas, en opinión de los encuestados, se da con el fin de evitar la discriminación de la población o los efectos de la pobreza se ha hecho invisibles en este entorno, por lo que los encuestados creen que el potencial del programa, pero son escépticos de la ruptura del ciclo de llamadas la pobreza intergeneracional.

Palabras clave: Programa de subsidio familiar; Asistencia a la escuela; la práctica DOCENTE.

\section{INTRODUÇÃo}

O Programa Bolsa Família (PBF), criado em 20 de outubro de 2003, por meio da Medida Provisória 132 e posteriormente convertido em lei, por ocasião da aprovação em 9 de janeiro de 2004, da lei 10.836, no primeiro mandato do presidente Lula (2003/2006), faz parte de um conjunto de políticas de proteção social não contributivas geradas a partir da integração de diversos Programas de Transferência de Renda - PTRs existentes até então, como o Bolsa-Escola, Bolsa-Alimentação, Vale-Gás e Cartão-Alimentação. Na compreen- 
são de Rocha (2013), pode-se dizer que há certo paralelismo em relação aos dois sistemas federais de transferências de renda assistenciais focalizados nos mais pobres. De um lado, o programa voltado aos idosos e portadores de deficiência, Programa de Benefício de Prestação Continuada (BPC), previsto na Constituição Federal de 1988. De outro, os chamados "novos" programas focados em famílias pobres com crianças, da qual o PBF faz parte, cuja gênese remonta às experiências municipais de programas de transferência de renda da década de $1990 .^{1}$

Como já mencionado, o PBF é um Programa de Transferência de Renda condicionado do Governo Federal que atende a famílias em situação de pobreza ou extrema pobreza no país, definidas pelo programa como aquelas que possuem renda mensal per capita de R $\$ 170,00$ e $\mathrm{R} \$ 85,00$ respectivamente. Os elegíveis a participarem do PBF podem receber dois tipos de benefícios, o básico e o variável. O benefício básico, de $\mathrm{R} \$ 85,00$, é destinado às famílias extremamente pobres, ou seja, as que têm renda per capita inferior a R \$ 85,00. O benefício variável é destinado às famílias que têm em sua composição, gestantes, nutrizes, crianças ou adolescentes. Para cada criança e adolescente entre 0 e 15 anos de idade é destinado um valor de R \$39,00 mensais limitado ao máximo de cinco benefícios por família. Há também o benefício variável destinado aos adolescentes entre 16 e 17 anos de idade que recebem mensalmente $\mathrm{R} \$ 46,00$, neste caso, limitado a dois benefícios por família. Há também o benefício variável destinado à superação da extrema pobreza, calculado de acordo com a renda e quantidade de pessoas da família, para garantir que a família ultrapasse o piso de $\mathrm{R} \$ 85,00$ de renda mensal per capita para romper a linha da extrema pobreza de acordo com os critérios do programa. $^{2}$ Sem negar seus efeitos positivos, autores como Rocha (2013), Lavina (2006) questionam a capacidade de programas de transferências de renda focalizados enfrentarem problemas tão estruturais como a pobreza e a desigualdade. Na visão desses autores, programas de transferência de renda podem amenizar parte desses problemas, mas não podem ter a pretensão de resolvê-los. Veremos, na análise das entrevistas, como essa compreensão está presente na fala dos gestores participantes dessa investigação.

Para receber o benefício do PBF é necessário o cumprimento de condicionalidades nas áreas de saúde, como o exame pré-natal e acompanhamento nutricional, e na área da educação, como a frequência escolar. Para famílias que têm em sua composição crianças e adolescentes de 0 a 15 anos de idade, a frequência escolar exigida é de $85 \%,{ }^{3}$ superior, portanto, à exigida na Lei de Diretrizes e Bases da Educação Nacional, ${ }^{4}$ que é de $75 \%$. Nas famílias que têm em sua composição jovens de 16 e 17 anos de idade, a frequência escolar mínima exigida destes é de $75 \%$. A exigência de frequência mínima escolar presente no desenho PBF, e em outros programas congêneres, se fundamenta na compreensão de que o

\footnotetext{
1 Não será discutido neste artigo o processo de formulação e implantação das experiências municipais de programas de transferência dos anos 90 do século passado e como estes se relacionaram com a formulação do PBF. O leitor poderá encontrar maiores informações nesse sentido consultando Rocha (2013), Fonseca (2001), Silva, Yazbek, \& Di Giovanni (2007), Cohn (2012), entre outros.

Valores referentes ao mês de novembro de 2016 (MDS, 2016).

Lei 10.836/04, Artigo $2^{\circ}$. III e Artigo $3^{\circ}$. § único.

4 Lei 9.394/96, Artigo 24 VI.
} 
acesso e a permanência na escola seriam um fator preponderante para o enfrentamento da chamada reprodução intergeracional da pobreza. Em outro trabalho, Pires (2013) faz um balanço sobre as objeções em relação à capacidade dessa condicionalidade educacional em lidar com problemas dessa envergadura. De qualquer forma, o PBF é um programa que aposta e valoriza a educação como forma de enfrentamento da pobreza.

Este artigo apresenta resultados de uma investigação que entrevistou gestores, diretores e coordenadores pedagógicos de quatro escolas municipais de Campinas (SP) localizadas em regiões de maior vulnerabilidade social, de acordo com o Índice Paulista de Vulnerabilidade Social - IPVS do Sistema Estadual de Análise de Dados - Fundação SEADE, e que atingiram o Índice de Desenvolvimento da Educação Básica (IDEB) projetado para 2013. A pesquisa teve como objetivo identificar se, em escolas com alunos bolsistas do PBF e relativamente bem avaliadas pelo IDEB, haveria algum tipo de discussão ou de prática pedagógica relacionada aos beneficiários que fosse além do registro do cumprimento da frequência escolar. De igual maneira, nos interessava compreender como a exigência de frequência escolar mínima para alunos beneficiários do PBF era percebida pelos seis gestores de quatro escolas localizadas em áreas de maior vulnerabilidade social no município considerado.

$\mathrm{O}$ texto exibe as principais falas dos seis gestores de escolas municipais do município de Campinas (SP) entrevistados no primeiro semestre de 2015. Análise dos resultados das entrevistadas indica que os gestores, apesar de apresentarem maior compreensão sobre o desenho do PBF, se comparados aos professores entrevistados por ocasião da pesquisa de Flores (2015), têm conhecimento em relação ao PBF quase que exclusivamente relacionado ao controle da frequência escolar, o que de certa forma é compreensível se levarmos em consideração que a frequência escolar, como condicionalidade ao recebimento do benefício, está intimamente ligada ao trabalho desses profissionais. Os resultados da pesquisa apontam também para a necessidade de maiores reflexões a respeito do desenho do programa em sua vivência nas escolas, especialmente, na relação entre educação e saída da pobreza, uma vez que, levando-se em consideração a fala dos gestores, a frequência escolar por si só não garante o rompimento do chamado ciclo intergeracional da pobreza.

\section{MÉTODO}

Para a realização deste trabalho, selecionamos as escolas a serem pesquisadas, tendo como ponto de partida inicial os resultados obtidos pelas escolas públicas municipais de Campinas (SP) que participaram da Prova Brasil, em 2013, e obtiveram resultados positivos no IDEB projetado para aquele ano. ${ }^{5}$

\footnotetext{
5 As escolhas de escolas municipais e do indicador IDEB nesta pesquisa se justificam pelo fato de que as escolas Estaduais participam também de uma avaliação chamada Sistema de Avaliação de Rendimento Escolar do Estado de São Paulo - SARESP - que compõe o Índice de Desenvolvimento da Educação de São Paulo - IDESP. Bons resultados em tal índice interessam aos professores e gestores das escolas estaduais, pois o governo paulista remunera com bônus pecuniário os professores da rede estadual que atingem os objetivos propostos, o que pode levar a um esforço maior para atingir o IDESP em detrimento do IDEB. Ver Colombo (2015, p. 80), Fernandes e Gremaud (2009, p. 213-238).
} 
Em 2013, 40 escolas urbanas municipais em Campinas-SP tiveram alunos da $4^{\mathrm{a}}$. série $/ 5^{\circ}$. ano participando da Prova Brasil, das quais 22 atingiram o IDEB projetado para aquele ano. De 37 escolas municipais com alunos da $8^{\mathrm{a}}$. série $/ 9^{\circ}$. ano que participaram da Prova Brasil, nove atingiram o IDEB Projetado para aquele ano. Assim, 31 escolas municipais participantes da Prova Brasil atingiram o IDEB projetado para 2013, sendo sete delas concomitantemente em ambos os ciclos.

A fim de delimitarmos o lócus deste estudo, tendo em vista que pressupomos que escolas que possuem um maior número de alunos beneficiários do PBF estariam em áreas de maior vulnerabilidade social, utilizamos o Índice Paulista de Vulnerabilidade Social IPVS da Fundação Sistema Estadual de Análise de Dados (SEADE). Tal índice leva em sua composição variáveis de natureza socioeconômica e demográfica, divide os municípios paulistas em sete grupos censitários: de baixíssima vulnerabilidade (Grupo 1) até vulnerabilidade muito alta (Grupo 6). O grupo 7 é composto exclusivamente por grupos censitários localizados em áreas rurais.

Das 31 escolas que atingiram o IDEB projetado para 2013, cinco estão localizadas em regiões de média vulnerabilidade (Grupo 4) e, portanto, foram definidas como locais privilegiados para esta pesquisa. Conseguimos autorização dos gestores das escolas para essa pesquisa em quatro, das cinco escolas municipais que atingiram o IDEB projetado para 2013 e que se encontram em áreas de maior vulnerabilidade social de acordo com o mapa do IPVS da Fundação SEADE, ou seja (Grupo 4). Para identificar as práticas pedagógicas adotadas nesses espaços e as percepções dos gestores em relação ao $\mathrm{PBF}$, recorremos às técnicas de entrevistas semiestruturadas, análise documental e observação de campo.

\section{Discussão dos RESUltados}

No tocante às entrevistas com os gestores, estes tiveram suas identidades preservadas e foram identificados em relação às escolas onde trabalham. As escolas foram identificadas como E1, E2, E3, e E4. Os entrevistados foram identificados pelo número de cada escola, o primeiro entrevistado da Escola 1 é o Entrevistado 1.1, o primeiro da Escola 2 é o Entrevistado 2.1, o segundo, Entrevistado 2.2 e assim sucessivamente. Nas escolas $1 \mathrm{e}$ 4, tivemos um entrevistado, pois o quadro de gestores estava incompleto. A caracterização geral dos entrevistados se encontra no Quadro 1. O roteiro de entrevista foi composto por três blocos, o primeiro buscou caracterizar o entrevistado e sua família, o segundo suas percepções acerca do PBF e o último compreender as práticas pedagógicas adotadas ou não nas escolas.

As escolas participantes da pesquisa localizam-se na região sudoeste de Campinas (SP), em bairros distantes do centro da cidade, foram inauguradas na primeira metade da década de 1980 e possuem entre 371 (E1) e 1.158 (E2) alunos. De acordo com os indicadores educacionais do INEP, ${ }^{6}$ essas escolas têm entre 23,5 alunos nas $4^{\text {as }}$ séries e 31 alunos no

6 Para saber como são construídos os indicadores educacionais, consultar http://portal.inep.gov.br/indicadores -educacionais. 
$9^{\circ}$. ano, por sala de aula. No Brasil, esse número é 22,4 nas $4^{\text {as }}$ séries e 27,3 no $9^{\circ}$. ano. Essas escolas têm entre 4 e 5,3 horas aula diárias por série, números compatíveis com as demais escolas brasileiras que têm entre 4,4 e 4,7 horas diárias de aula, com a ressalva das 4 horas diárias de aula transcorrerem em escolas que adotam turno intermediário entre os horários da manhã e da tarde, o que os professores chamam de "Turno da Fome". Nas escolas visitadas, 95,4\% dos professores têm ensino superior, esse percentual é maior que a média das escolas brasileiras, que é de 79,0\%, maior também que o percentual nas escolas paulistas e campineiras, que é de $91,1 \%$ e $89,5 \%$ respectivamente (INEP, 2015).

As escolas apresentam taxa de distorção idade série entre 11,2\% e 15,8\% no Ensino Fundamental, números superiores aos verificados no Estado de São Paulo (7,6\%) e em Campinas (8,7\%), mas inferior à taxa verificada no Brasil, que é de $21,0 \%$. Essas escolas apresentam uma taxa de rendimento no geral entre $90,4 \%$ e $96,3 \%$, números semelhantes aos verificados nas demais esferas.

Quadro 1: Caracterização dos entrevistados.

\begin{tabular}{|c|c|c|c|c|c|c|}
\hline \multicolumn{6}{|c|}{ Escolas } & \multirow[b]{2}{*}{4} \\
\hline & 1 & & 2 & & 3 & \\
\hline Entrevistado & 1.1 & 2.1 & 2.2 & 3.1 & 3.2 & 4.1 \\
\hline Sexo & Feminino & Feminino & Feminino & Feminino & Feminino & Masculino \\
\hline Idade & 34 & 39 & 57 & 66 & 58 & 32 \\
\hline Cargo que ocupa & $\begin{array}{l}\text { Orien- } \\
\text { tadora } \\
\text { Pedagó- } \\
\text { gica }\end{array}$ & $\begin{array}{l}\text { Orienta- } \\
\text { dora Pe- } \\
\text { dagógica }\end{array}$ & Diretora & $\begin{array}{l}\text { Orientado- } \\
\text { ra Pedagó- } \\
\text { gica }\end{array}$ & Diretora & Diretor \\
\hline Estado Civil & Solteira & Casada & Casada & Casada & Casada & Casado \\
\hline Cor & Branca & Branca & Branca & Branca & Branca & Branca \\
\hline Filhos & 0 & 3 & 3 & 4 & 3 & 1 \\
\hline $\begin{array}{l}\text { Onde os filhos } \\
\text { estudam ou se } \\
\text { formaram? }\end{array}$ & $\mathrm{S} / \mathrm{I}$ & $\begin{array}{l}\text { Oficina } \\
\text { do Estu- } \\
\text { dante e } \\
\text { EDUCAP }\end{array}$ & $\begin{array}{c}\text { PUC } \\
\text { UNIP } \\
\text { ambas em } \\
\text { Campinas }\end{array}$ & $\begin{array}{c}\text { ESALQ, } \\
\text { UNESP } \\
\text { PUCC }\end{array}$ & $\begin{array}{c}\text { PUC e UNIP } \\
\text { ambas em } \\
\text { Campinas }\end{array}$ & Particular \\
\hline $\begin{array}{l}\text { Local de Nasci- } \\
\text { mento }\end{array}$ & $\begin{array}{l}\text { Campi- } \\
\text { nas-SP }\end{array}$ & $\begin{array}{l}\text { Campi- } \\
\text { nas-SP }\end{array}$ & $\begin{array}{c}\text { Campinas } \\
\text {-SP }\end{array}$ & $\begin{array}{l}\text { Santo An- } \\
\text { tonio de } \\
\text { Posse-SP }\end{array}$ & $\begin{array}{c}\text { Ituiutaba } \\
-\mathrm{MG}\end{array}$ & $\begin{array}{c}\text { São Paulo } \\
\text {-SP }\end{array}$ \\
\hline Formação & $\begin{array}{l}\text { Pedago- } \\
\text { gia }\end{array}$ & $\begin{array}{l}\text { Pedago- } \\
\text { gia }\end{array}$ & Pedagogia & Pedagogia & $\begin{array}{c}\text { Ped./Hist. e } \\
\text { Geo. }\end{array}$ & $\begin{array}{c}\text { Letras e } \\
\text { Pedagogia }\end{array}$ \\
\hline Universidade & $\begin{array}{l}\text { UNI- } \\
\text { CAMP }\end{array}$ & UNIP & $\begin{array}{c}\text { Faculdade } \\
\text { de Ouro } \\
\text { Fino-MG }\end{array}$ & $\begin{array}{c}\text { Faculdades } \\
\text { Integradas } \\
\text { Campos } \\
\text { Sales }\end{array}$ & $\begin{array}{c}\text { Anhanguera/ } \\
\text { UNIFAC }\end{array}$ & UNINOVE \\
\hline
\end{tabular}




\begin{tabular}{|c|c|c|c|c|c|c|}
\hline $\begin{array}{c}\text { Gostaria de ter } \\
\text { feito outro curso? }\end{array}$ & Não & Não & Não & Sim & Sim & Não \\
\hline $\begin{array}{c}\text { Pós-Graduação, } \\
\text { Curso }\end{array}$ & $\begin{array}{c}\text { Lato } \\
\text { Senso } \\
\text { Gestão } \\
\text { Escolar }\end{array}$ & $\begin{array}{l}\text { Lato Sen- } \\
\text { so } \\
\text { Psicope- } \\
\text { dagogia }\end{array}$ & $\begin{array}{l}\text { Lato senso } \\
\text { Gestão } \\
\text { Educacio- } \\
\text { nal/ Didá- } \\
\text { tica }\end{array}$ & $\begin{array}{l}\text { Lato Senso } \\
\text { Psicomo- } \\
\text { tricidade e } \\
\text { Psicoped. } \\
\text { Clinica e } \\
\text { inst. }\end{array}$ & $\begin{array}{l}\text { Lato Senso } \\
\text { Adm. Es- } \\
\text { colar }\end{array}$ & $\begin{array}{l}\text { Mestrado } \\
\text { em An- } \\
\text { damento } \\
\text { Strictu sen- } \\
\text { so Saúde e } \\
\text { Educação }\end{array}$ \\
\hline $\begin{array}{c}\text { Tempo que lecio- } \\
\text { nou }\end{array}$ & 14 Anos & 12 Anos & 24 Anos & $\mathrm{S} / \mathrm{I}$ & $\mathrm{S} / \mathrm{I}$ & 10 Anos \\
\hline $\begin{array}{l}\text { Tempo de exercí- } \\
\text { cio na função }\end{array}$ & 2 Meses & 6 Anos & 14 Anos & 20 Anos & 10 Anos & 4 Anos \\
\hline $\begin{array}{c}\text { Tempo nessa } \\
\text { escola }\end{array}$ & 3 Anos & 6 Anos & 14 Anos & 12 Anos & 4 Meses & 3 Anos \\
\hline $\begin{array}{c}\text { Grau de escolari- } \\
\text { dade do Pai }\end{array}$ & Primário & $4^{\mathrm{a}}$. Série & Ens. Fund. & $4^{a}$. Série & $4^{a}$. Série & $4^{a}$. Série \\
\hline $\begin{array}{c}\text { Grau de escolari- } \\
\text { dade da Mãe }\end{array}$ & Primário & $\begin{array}{c}\text { Formou } \\
\text { profes- } \\
\text { sora }\end{array}$ & Ens. Fund. & $4^{a}$. Série & $2^{a}$. Série & $4^{a}$. Série \\
\hline
\end{tabular}

Fonte: Organização dos autores com base nas entrevistas.

Considerando o perfil dos entrevistados(as), podemos notar que a gestão no ensino fundamental e médio nas escolas selecionadas é predominantemente exercida por mulheres - 5/6 dos entrevistados. Todos(as) são pedagogos(as), dois possuem, além dessa, outra formação na graduação. Três entrevistados(as) são orientadores(as) pedagógicos(as) e três diretores(as). Todos(as) declaram-se brancos(as).

De acordo com informações do quadro, verifica-se um acréscimo na escolaridade da atual e da nova geração (entrevistados e seus filhos) em relação às gerações anteriores (pais dos entrevistados). Os pais dos(as) entrevistados(as) tinham, em sua maioria, a $4^{\mathrm{a}}$. série. Os(as) entrevistados(as), em sua maioria, concluíram sua graduação e fizeram pósgraduação lato sensu em instituições privadas, e seus filhos, os que já chegaram à idade do ingresso no ensino superior, já o concluíram.

Em média, os(as) entrevistados(as) têm 15 anos de trabalho dedicados à educação, alguns gestores não conseguiram afirmar precisamente quando seu trabalho docente foi iniciado. A entrevistada 2.2 afirmou, por exemplo, estar entre docência e gestão há 24 anos na mesma escola.

Quanto ao tempo na função de orientador(a) pedagógica ou diretor(a), por ser um trabalho mais recente, todos conseguem afirmar com maior precisão o tempo dedicado a essa função, sendo, em média, de 9 anos, variando entre 2 meses e 20 anos. O tempo na escola, local da entrevista é, em média 6 anos, variando entre 3 meses e 14 anos.

Em relação à experiência na docência e na gestão por parte dos entrevistados(as), vale lembrar que os cargos ocupados pelos entrevistados(as) requerem 8 anos de efetivo 
exercício docente na carreira do magistério ou graduação superior de licenciatura plena em pedagogia somado a 6 anos de efetivo exercício docente na carreira do magistério, mais 2 anos de efetivo exercício de outros cargos ou funções próprias da carreira do magistério (CAMPINAS, 2011). Isso explica, em parte, a experiência dos entrevistados. Tal estrutura de progressão administrativa favorece que os professores mais antigos deixem as salas de aula e se tornem gestores.

Em síntese, os(as) gestores(as) entrevistados(as) são professores(as) com formação na área, com experiência de ensino e de administração e com especialização na área. Dedicam-se exclusivamente a esse trabalho e metade deles não teve experiências em outras áreas.

\section{PERCEPÇÕES dOS GESTORES SOBRE O PROGRAMA bOLSA FAMÍlia}

Analisaremos, neste bloco, as percepções dos entrevistados sobre o PBF, assim como suas experiências em relação aos filhos dos beneficiários dentro do ambiente escolar e suas propostas de melhoria para o Programa.

Em geral, os entrevistados desta pesquisa demonstram ter mais informações sobre o desenho do PBF em relação aos entrevistados na pesquisa de Flores (2015). Naquela pesquisa, os entrevistados eram professores e, nesta, são orientadores pedagógicos e diretores, e, assim, enquanto o trabalho daqueles está mais voltado para a sala de aula, o destes está mais voltado para questões relacionadas com o Programa, como, por exemplo, o registro da assiduidade dos alunos.

Sendo assim, ao questionar os entrevistados sobre o que sabem em relação ao PBF, as respostas dos entrevistados foram bem parecidas neste grupo.

As entrevistas apresentam pontos em comum e demonstram que os(as) entrevistados(as) sabem que o PBF é um benefício de assistência, mas não sabem o valor nem o número limite de beneficiários em cada família que fazem jus ao benefício. Pela natureza do seu trabalho, conhecem a condicionalidade de frequência escolar. Acreditam também que o benefício visa acabar com a evasão escolar e reduzir a participação da força de trabalho infantil na remuneração familiar.

O que eu sei né, do Bolsa Família, é que é uma renda fixa que a família recebe, por aluno né, e que isso está vinculado à questão da frequência, não digo do aproveitamento, mas da frequência, do aluno na escola. (Entrevistada 2.1)

A entrevistada apresenta ainda uma observação com caráter moralizante de utilização do valor pecuniário do benefício.

Eu acho que existem prós e contras, assim como tudo nessa vida, né, [...] e também tem famílias aqui que usam isso, essa verba, não pra criança em si entendeu, a gente sabe que tem outros encaminhamentos por aí né. (Entrevistada 3.1). 
Percebe-se que há um caráter regulador sobre a forma que a família deve gastar o dinheiro. Esse sentimento moral de como se deve gastar o benefício também está presente nas falas dos beneficiários em outra pesquisa nesse mesmo município (PIRES, 2013). Apesar de a condicionalidade ser em relação à frequência da criança, o programa não normatiza em que ou com quem a família deve gastar o dinheiro recebido. A criança, assim, não é o destinatário final do benefício e sim a família (SILVA, 2016). ${ }^{7}$

Ao falarem das suas percepções sobre a condicionalidade em educação, todos os entrevistados afirmaram ser positiva, cada entrevistado argumentou com considerações diversas, que podem ser apresentadas em dois grupos.

O primeiro deles está intimamente ligado ao ato de ir à escola, à criação do hábito e por conseguinte do sequenciamento das aprendizagens (Entrevistada 1.1 e Entrevistada 2.1). Leva-se em conta, neste caso, apenas a frequência escolar, como forma de permitir um maior sequenciamento.

O segundo grupo de respostas mostrou que o incremento de tal frequência permite uma aproximação da família (Entrevistada 2.2 e Entrevistada 3.2) e da comunidade na escola, sendo que no primeiro caso de forma punitiva, "pois assim os pais vêm à escola, pois têm medo de perder o benefício". De qualquer maneira, entende a entrevistada que os resultados obtidos com tal aproximação são positivos.

Concordamos que seja inegável a importância da participação das famílias no ambiente escolar, assim como sugerem Menezes-Filho e Ribeiro (2009), Alencar et al. (2015) e Osti (2016), porém se percebe, por vezes, um distanciamento entre a realidade da escola e a rotina dos pais em relação ao horário de reuniões. Mesmo que a escola se esforce para alcançar seus objetivos de trazer a família a participar da escola, algumas peculiaridades sociais se tornam empecilhos, como atesta a seguinte fala.

É eu valorizo essas coisas, mas eles passam sempre correndo, a mãe às vezes não tem o pai, ela cuida sozinha da casa e é tão difícil para essa mulher, ela perder um dia de serviço, mesmo eu dando um atestado o que é que ela vai falar pro patrão? Eu sei disso, é difícil. Aí eu tento ver se eu consigo fazer umas reuniões à noite, mas também aí o lugar é periferia... (Entrevistada 3.2)

Outra questão apresentada aos(as) entrevistados(as) foi sobre a contribuição do PBF para o enfrentamento da pobreza. As entrevistas sugerem que se espera dos beneficiários determinado padrão de comportamento, o de maltrapilho, faminto, abandonado pela família (Entrevistada 1.1). O que não é verificado no cotidiano das escolas, segundo as próprias entrevistas.

Eu teria a visão assim de que a criança que recebe Bolsa Família ela tem que vir malvestida, ela passa fome em casa, então ela vem para escola naquela ânsia de chegar logo o intervalo pra comer, e eu não verifico isso. (Entrevistada 1.1)

De acordo com a Lei 10836/04, família é a unidade nuclear, eventualmente ampliada por outros indivíduos que com ela possuam laços de parentesco ou de afinidade, que forme um grupo doméstico, vivendo sob o mesmo teto e que se mantém pela contribuição de seus membros. 
A Entrevistada 2.1 utiliza, em sua fala, um discurso que coloca em voga a ideia de que os beneficiários do PBF vivem só da renda do benefício.

Essa questão do vínculo, num ser uma ferramenta, não ser um apoio, ser só uma coisa, vamos supor, a família só dependa disso, tem que ser um complemento, não pode se limitar só a essa contribuição. (Entrevistada 2.1)

Segundo Schwartzman (2009), essa ideia de que dar dinheiro ao pobre estimula o ócio e a preguiça vem desde o século XVIII, quando da abolição das PoorLaws. Esse discurso teve grande força nos anos de 1960 nos Estados Unidos, por ocasião dos programas contra a pobreza, quando aumentou a discriminação contra os pobres e contra o governo democrata que os ajudava, "a generosidade do governo corroía a vontade de trabalhar, solapava a vida familiar estável e estimulava comportamentos ilegais" (KOWARICK, 2009, p. 37). Naquela época, acreditava-se, inclusive, que essas desestabilidades familiares, criadas pelos benefícios sociais, contribuíam para o aumento de filhos ilegítimos. Veremos que tal discurso ainda ecoa. Uma entrevistada, ao propor melhorias ao PBF, afirmou que:

O governo precisa investir em Políticas Públicas de planejamento familiar [...] então eu acho que o governo deveria atrelar também o auxílio a um comportamento de controle de natalidade, né. (Entrevistada 1.1)

Imagina ela que o Programa, mesmo que indiretamente, incentiva a natalidade, tendo em vista que parte do benefício é condicionado ao número de filhos. Porém, dados do Programa Nacional por Amostras de Domicílio - PNAD do Instituto Brasileiro de Geografia e Estatística - IBGE afirmam que o número de filhos nas famílias reduziu no Brasil, principalmente nas famílias beneficiárias do PBF (MDS, 2016).

Sabemos que o recebimento de um benefício social não aumenta o ócio ou a preguiça, os valores são complementares. Segundo o Ministério do Desenvolvimento Social, 75,4\% dos beneficiários do Programa trabalham (MDS, 2016). Porém, esse discurso está enraizado no ideário popular e aparece amiúde nas entrevistas. "Eu faria um vínculo com o trabalho, se não trabalhar não recebe" sugere a Entrevistada 3.1, ao propor melhorias para o Programa.

Afirma a Entrevistada 2.2 que o bairro tem algumas necessidades sociais coletivas, como saúde e lazer, sendo que solucionar tais problemas seria uma melhor saída para o enfrentamento da pobreza, e apresenta isso como melhorias para o Programa. Acredita também que o dinheiro do benefício é algo paliativo. Ao analisarmos os objetivos do PBF, temos que os valores pagos mensalmente aos beneficiários estão relacionados a esse fim descrito pela entrevistada: "Esse eixo (transferência de renda diretamente às famílias) garante o alívio mais imediato da pobreza" (MDS, 2016). A eventual superação da pobreza vem da articulação desse objetivo (transferir renda) com os demais, ou seja, favorecer o acesso aos direitos sociais por meio do cumprimento das condicionalidades em saúde e educação.

A Entrevistada 3.1 afirmou que o PBF auxilia no enfrentamento da pobreza, cumprindo, assim, com um dos objetivos ao qual se propõe o Programa, mas acredita que falta 
maior acompanhamento do governo. Não levou em consideração que o lançamento de faltas dos alunos para conferência do cumprimento da condicionalidade pode ser considerado uma forma de acompanhamento.

A Entrevistada 3.2, por sua vez, não mencionou os benefícios monetários recebidos pelos beneficiários, mas enfatizou em sua resposta a presença do aluno na escola. Para ela, esta é a verdadeira importância de participar do Programa. Inclusive sugere que o Programa dê mais autonomia aos diretores das escolas quanto ao lançamento das faltas dos alunos, pois estes conhecem de forma mais próxima a realidade dos mesmos.

O pai fez de tudo, se explicou e depois a gente faz com que o aluno recupere, vale, porque não, acho que se tivesse escrito essa autonomia, o diretor tem outra visão, porque é ele que está aqui, ele conhece cada aluno dele, conhece cada história das famílias, então devia ter essa autonomia assim pros diretores. (Entrevistada 3.2).

Ao tratarmos das diferenças e semelhanças entre crianças beneficiárias e as não beneficiárias do PBF, temos que:

Não necessariamente a criança tem assim, vamos supor, o Bolsa Família e tem
problema, não tem nada a ver uma coisa com a outra, isso depende da criança,
depende da família, não tem uma demarcação, o aluno é único, independente,
se ele tem que estar dentro de um padrão de comportamento, de aprendizagem,
ele é único, então, a história de vida dele. (Entrevistada 2.1)

A fala da entrevistada indica que, apesar de reconhecer que o aluno é único em suas individualidades, ele deve estar dentro de um padrão de comportamento esperado. Esse padrão de comportamento é o dominante, o legitimado pela escola e que nega, muitas vezes, o comportamento dos filhos dos pobres por meio de pedagogias de dominação/subalternização das quais fala Arroyo (2014, p. 37-70), ao tratar de práticas pedagógicas voltadas aos Outros Sujeitos.

Um ponto a ser destacado na fala da Entrevistada 3.1 é em relação à uniformização dos alunos. As roupas que o poder público fornece tornam as desigualdades invisíveis, essas desigualdades poderiam ser explicitadas na forma como os mais pobres se vestem.

Tem uma parcela grande, assim, eu posso considerar uma pobreza e então esses alunos se misturam com os outros e não dá pra falar mesmo porque o material escolar eles recebem, uniforme eles recebem, então não tem como você diferenciar, ah o aluno vem com uma roupa, ou uma calça Jeans melhorzinha e aquele coitadinho vem daquele jeito, não tem isso. (Entrevistada 3.1)

A Entrevistada 2.1 afirma que participar do programa faz diferença aos alunos, pois, além da aprendizagem, eles têm refeições. 
Lógico que faz, porque aqui nós oferecemos, além da aprendizagem, do conhecimento, têm as refeições a gente tem o outro lado, a gente sabe que tem famílias aqui que têm condições bem precárias, então eu acho que faz diferença. (Entrevistada 2.1)

Essa fala representa a ideia de que as escolas para os filhos do pobre, muitas vezes, se tornam locais de acolhimento e de satisfação de necessidades básicas como comer, se vestir, ter um material escolar, como afirma Libâneo (2012). A escola, como local de acolhimento para os pobres, estaria deixando de lado a qualidade do ensino oferecido, contribuindo assim para reforçar os mecanismos de exclusão social.

Outra questão apresentada aos entrevistados era se existem práticas pedagógicas voltadas aos alunos beneficiários do Programa Bolsa Família. As respostas foram semelhantes entre os entrevistados. Todos relataram que não há práticas pedagógicas voltadas especificamente aos alunos beneficiários do Programa. Alguns, como se verá a seguir, demonstraram surpresa com a indagação, pois não tinham pensado nessa possibilidade.

Ainda que não existam práticas pedagógicas voltadas aos beneficiários, há outras práticas que levam em consideração as singularidades dos alunos.

A seguir apresentamos um quadro sintético com as respostas dos entrevistados.

Quadro 2. Práticas pedagógicas voltadas à aprendizagem de alunos beneficiários do Programa Bolsa Família.

\begin{tabular}{|c|c|}
\hline Entrevistado & Por que não existem práticas? \\
\hline $\begin{array}{l}\text { Entrevistada } \\
1.1\end{array}$ & $\begin{array}{l}\text { Por que nunca pensou sobre isso, olha três anos que eu estou aqui, na verdade, a } \\
\text { gente nunca levantou nenhum questionamento a respeito dos alunos bolsistas. }\end{array}$ \\
\hline $\begin{array}{l}\text { Entrevistada } \\
2.1\end{array}$ & $\begin{array}{l}\text { Independentemente de ser do Bolsa Família ou não, ele vai ser atendido pelo } \\
\text { reforço escolar, não existe uma diferenciação e um rótulo. }\end{array}$ \\
\hline $\begin{array}{l}\text { Entrevistada } \\
\quad 2.2\end{array}$ & $\begin{array}{l}\text { Eu não vejo diferencial, é que eu estou numa área em que todos aqui, na ver- } \\
\text { dade, a comunidade toda aqui precisaria receber o Bolsa Família. }\end{array}$ \\
\hline $\begin{array}{l}\text { Entrevistada } \\
\quad 3.1\end{array}$ & Os professores não sabem quem são esses alunos, a gente não sabe quem são. \\
\hline $\begin{array}{l}\text { Entrevistada } \\
\quad 3.2\end{array}$ & $\begin{array}{l}\text { Acho que a criança se sentiria diferente dentro da escola, se sentiria diferente, } \\
\text { aquilo que eu falo tem uma ponta de preconceito, a criança se sentiria diferente. }\end{array}$ \\
\hline $\begin{array}{l}\text { Entrevistado } \\
\quad 4.1\end{array}$ & $\begin{array}{l}\text { Porque não há essa dissociação dentro da escola, quem recebe e quem não } \\
\text { recebe, eu acho isso nem correto. }\end{array}$ \\
\hline
\end{tabular}

Fonte: Organização dos autores com base nas entrevistas.

As justificativas sobre os motivos que levam as equipes gestoras das escolas a não adotarem práticas pedagógicas voltadas a alunos beneficiários do PBF podem ser divididas em dois grupos. 
No primeiro, justifica-se a inexistência de práticas específicas a fim de evitar discriminação maior tanto por parte dos profissionais quanto por parte dos alunos. A responsabilidade que recai sobre os ombros das crianças em ter que vir à escola para que os pais não percam o benefício é relatado pela Entrevistada 2.2. Assim como o sentimento de vergonha, talvez de fracasso que é sentido desde cedo pela criança, por sua família precisar de ajuda, mesmo que esteja estudando em um local em que a maioria é beneficiária do Programa. Ao que parece, tudo isso inibe qualquer ação pedagógica que exponha ainda mais tais "fraquezas" associadas à pobreza.

Um segundo grupo de respostas sugere que a escola conta com instrumentos que são capazes de invisibilizar quaisquer diferenças. Como disponibilizar uniforme para alunos, distribuição de material escolar, assim como o discurso de que todos são iguais, ou que não dispensam tratamento diferenciado.

\section{CONSIDERAÇÕES FINAIS}

De forma mais ampla, o objetivo da pesquisa era identificar se existem práticas pedagógicas em escolas localizadas em regiões de maior vulnerabilidade voltadas aos beneficiários do Programa Bolsa Família que atingiram o IDEB projetado para o ano de 2013, a partir das falas de gestores das escolas pesquisadas. Além disso, a investigação visou analisar o grau de conhecimento dos gestores das escolas em relação ao Programa Bolsa Família.

A partir da análise das entrevistas, pode-se afirmar que não existem práticas pedagógicas voltadas aos alunos beneficiários do PBF e tal questão causou surpresa aos entrevistados, demonstrando que até o momento da entrevista não tinham refletido sobre tal possibilidade. Como vimos, a inexistência de tais práticas foi justificada em duas vertentes. A primeira a fim de evitar discriminação maior tanto por parte dos profissionais quanto por parte dos alunos. A segunda sugere que a escola conta com instrumentos que são capazes de invisibilizar quaisquer diferenças.

Nas escolas pesquisadas, não há qualquer prática que estabeleça relação específica com os beneficiários de maneira direta ou indireta por parte da escola. $\mathrm{O}$ único exemplo foi de uma escola que chama os pais para cobrar a frequência dos filhos, em caráter mais punitivo, e aproveita o ensejo para falar de questões pedagógicas.

Precisamos considerar que o desenho do Programa Bolsa Família não prevê que as escolas realizem quaisquer atividades além da verificação da frequência escolar. $\mathrm{O}$ que as entrevistas sugerem é que as escolas selecionadas, em relação ao PBF, estão de fato cumprindo com suas funções, verificação da frequência, e nada mais. A ausência de qualquer estratégia envolvendo professores, alunos e pais, para tratar especificamente do PBF indica, pelo menos a partir das experiências das escolas selecionadas, que a relação entre educação e saída da pobreza no âmbito do programa, tem se restringido exclusivamente à cobrança da frequência escolar, algo considerado insuficiente até pelos próprios entrevistados.

Percebemos também que os gestores reconhecem os fatores que podem aperfeiçoar a relação entre ensino e aprendizagem, como a participação da família e o uso de métodos que promovam o diálogo e a participação do aluno, assim como da comunidade, embora 
existam algumas peculiaridades do trabalho em escolas localizadas nessas áreas que acabam dificultando essas ações. No entanto, seja os familiares, seja os alunos, não participam diretamente na formulação de tais práticas.

Em relação ao PBF, todos os entrevistados têm compreensão sobre a exigência de condicionalidades em educação, inclusive destacando diferenças entre frequência e aproveitamento. Ainda podemos anotar que todos os entrevistados afirmaram ser positiva uma condicionalidade desse tipo.

Concluímos que, na busca de práticas pedagógicas voltadas aos alunos beneficiários do Programa, encontramos, nesta pesquisa, equipes gestoras que acreditam no potencial do PBF em relação ao seu poder de transformação da realidade. Em geral, os entrevistados conhecem o Programa e sabem da exigência da condicionalidade em educação, mas consideram que a frequência não é o suficiente. Observam que o Programa deve aliviar a pobreza, mas são céticos em relação ao rompimento do ciclo intergeracional da pobreza, alguns com visões mais moralistas e outros com visões mais abrangentes, ao mostrar as necessidades de articular a pobreza com outras políticas públicas. Algumas entrevistas mostraram sensibilidade em relação ao fato de que o não cumprimento das condicionalidades pode ter relações com problemas que vão além da vontade dos pais e dos filhos.

\section{REFERÊNCIAS}

ALENCAR, E. M. et. al.Criatividade no Ensino Fundamental: Fatores Inibidores e Facilitadores segundo Gestores Educacionais. Psicologia: Teoria e Pesquisa, Brasília, 31, n. 1, jan./mar. 2015, 105-114.

ARROYO, M. G. Outros sujeitos, outras pedagogias, 2. ed. Petrópolis: Vozes, 2014. ISBN 978-85-326-4448-0.

CAMPINAS. Diario Oficial do Municipio. www.campinas.sp.gov.br, 22 dez. 2011. Disponivel em: <http://www.campinas.sp.gov.br/uploads/pdf/878537254.pdf $>$. Acesso em: 6 maio 2016 .

COLOMBO, B. Prova Brasil e SARESP: repercusões na construção da qualidade da educação na percepção de professores e gestores de escolas públicas estaduais do município de Campinas-SP. Pontifícia Universidade Católica. Campinas-SP, p. 156, 2015.

FERNANDES, R.; GREMAUD, A. P. Qualidade da Educação: Avaliação, Indicadores e Metas. In: VELOSO, F., et al. Educação Básica no Brasil. Rio de Janeiro: Elsevier, 2009, p. 213-238.

FLORES, D. "A gente não tem noção": pontos de vista de professores de uma escola pública de Campinas-SP em relação ao Programa Bolsa Família. Pontifícia Universidade Católica. Campinas-SP, p. 186, 2015.

INEP. Instituto Nacional de Estudos e Pesquisas Educacionais Anísio Teixeira. Disponível em <http: //portal.inep.gov.br/indicadores-educacionais, 2015>. Acesso em: 5 outubro 2015. 
KOWARICK, L. Viver em Risco. Sobre a vulnerabilidade socioeconômica e civil. São Paulo: 34, 2009, 320 p.

LIBÂNEO, J. C. O Dualismo Perverso da escola pública brasileira: escola do conhecimento para os ricos, escola do acolhimento social para os pobres. Educação e Pesquisa, São Paulo, v. 38, p. 13-28, 2012.

MDS. Ministério do Desenvolvimento Social. <www.mds.gov.br>, 2016. Disponível em: $<$ http://mds.gov.br/assuntos/bolsa-familia/o-que-e/como-funciona $>$. Acesso em: 4 nov. 2016.

MENEZES-FILHO, N.; RIBEIRO, P. Os Determinantes da Melhoria do Rendiemnto Escolar. In: VELOSO, F., et al. Educação Básica no Brasil. Rio de Janeiro: Elsevier, 2009, p. 171-188.

NERI, M. C. O Paradoxo da evasão e as motivações dos sem Escola. In: VELOSO, F., et al. Educação Básica no Brasil. Rio de Janeiro: Elsevier, 2009, p. 25-50.

OSTI, A. Contexto familiar e o desempenho de estudantes do $5^{\circ}$. ano de uma escola no interior de São Paulo. Educação Temática Digital, Campinas-SP, 18, abr.jun. 2016, 369-383.

PIRES, A. Relações de troca e reciprocidade entre os participantes do Programa Bolsa Família em Campinas-SP. Revista de Ciências Sociais, On line, n. 38, p. 171-195, abril 2013. ISSN 1517-5901.

. A.; SILVA, A. L. O Programa Bolsa Família: Percepções de Mães beneficiárias sobre educação e a possível cosntrução de uma vida nova para seus filhos. Comunicações, Piracicaba, jan./jun. 2015, 7-25.

ROCHA, S. Transferências de renda no Brasil: o fim da pobreza? Rio de Janeiro: Elsevier, 2013, 216 p. ISBN 978-85-352-7132-4.

SCHWARTZMAN, S. Bolsa Familia: Mitos e Realidades. Interesse Nacional, dez 2009, 20-28.

SEADE. Fundação Sistema Estadual de Análise de Dados. <http: //www.seade.gov.br/>, 2015. Acesso em: 10 agosto 2015.

SILVA, M. O. D. S. et al. A Família enquanto público-alvo do Bolsa Família. In: SILVA, M. O. D. S. E.O Bolsa Família: Verso e Reverso. Campinas: Papel Social, 2016, p. 67-82.

DAdos dos Autores:

LiNEU SANTOS

Licenciado em Pedagogia pelo Centro Universitário Internacional (Uninter), Mestre em Educação pela Pontifícia Universidade Católica de Campinas (PUC-Campinas). Pontifícia 
Universidade Católica de Campinas - PUC-Campinas. Campinas/SP - Brasil. lineu_mp@ hotmail.com.

\section{ANdré Pires}

Pós-Doutorado na Universidade de Princeton (Estados Unidos) em 2017. Graduado em Ciências Sociais pela Unicamp (1993), mestrado em Antropologia Social pela Unicamp (1998) e doutorado em Ciências Sociais pela Unicamp (2004). Professor do Quadro Permanente do Programa de Pós-Graduação em Educação da Pontifícia Universidade Católica de Campinas. Campinas/SP - Brasil. anpires@puc-campinas.edu.br.

Submetido em: 24-4-2017

Aceito em: $26-4-2018$ 